FROM THE EDITOR-IN-CHIEF DESK

\title{
Present, Past and Future of Nuclear Medicine in Bangladesh
}

\author{
Mizanul Hasan \\ Professor, National Institute of Nuclear Medicine and Allied Sciences, \\ Bangladesh Atomic Energy Commission, Dhaka.
}

Address for Correspondence: Prof. Mizanul Hasan, National Institute of Nuclear Medicine and Allied Sciences, Bangladesh Atomic Energy Commission, BSM Medical University, Dhaka, Bangladesh.

Email:drhasan_m@yahoo.com

The history of Nuclear Medicine in Bangladesh is quite old. More than 50 years have passed the first nuclear medicine center started its journey in this country in a mere tin shed building in Dhaka Medical College Hospital. The center was then named as Radioisotope Center. This is quite interesting that when nuclear medicine was still in infant stage in global scenario, Bangladesh got its first center and started using radioisotopes for management of thyroid diseases. Before independence of Bangladesh, two more centers were established outside Dhaka, one at Rajshahi and other at Chittagong. This indicates far sightedness of our older generation.

At present more than 20 nuclear medicine centers are functioning in different parts of the country covering almost all the corners. While most of the centers are run by Bangladesh Atomic Energy Commission (BAEC), a few private hospitals have also come forward with nuclear medicine departments. In government sector also a few centers have been opened including at Dhaka Combined Military Hospital. Globally in last few decades nuclear medicine has developed rapidly with introduction of new instruments like SPECT, SPECT-CT, SPECT-MRI or PET technology. At the same time many new radiopharmaceuticals have also been developed for diagnosis as well as for therapy. In Bangladesh now almost all the centers have one or more SPECT or SPECT-CT cameras. PET-CT has already been established in two private hospitals of Dhaka city giving services to the patients. The National Institute of Nuclear Medicine \& Allied Sciences (NINMAS) has already got the PET-CT and now waiting for installation. One more PET-CT has also been ordered for Institute of Nuclear Medicine \& Allied Sciences (INMAS), Dhaka and expected to arrive shortly. The country has one cyclotron at present in a private hospital. Another one with bigger capacity will be installed at NINMAS for its own demand which will also be able to provide PET tracers to INMAS, Dhaka and other PET centers expected to be established in Dhaka city.

Rapid development has occurred in health services in Bangladesh in last decade. Keeping pace with that nuclear medicine services are also expanding. But if we compare it to other developed or developing countries of Southeast Asia, still we are lagging far behind. Till now our nuclear medicine is mainly based on two common isotopes, Tc-99m \& I-131. The other isotopes like I123 , gallium, thallium, samarium or rhenium, which are now routinely used by many centers, are 
not yet available in our country. Even isotopes like P-32 or Cr-51 are not available for long time. Till today we are importing kits or radiopharmaceuticals. The long waited local kits from radioisotopes production division of BAEC are still in research phase. Besides all shortage of manpower is probably the most important obstacle in expansion or development of nuclear medicine in Bangladesh. Most of the centers are running with shortage of manpower as well as with equipments to serve the large number of patients attending the centers. Bangladesh definitely needs expansion of nuclear medicine facilities to serve more than 160 million people of the country. However mere opening of the new centers will not serve the purpose. Society of Nuclear Medicine, Bangladesh (SNMB) should play its role so that this sophisticated and specialized service of medicine is properly expanded. 